\title{
Differential binding studies applying functional protein microarrays and surface plasmon resonance
}

\author{
Harald Seitz ${ }^{1}$, Silke Hutschenreiter ${ }^{2}$, Claus Hultschig ${ }^{1}$, Carsten Zeilinger ${ }^{2}$, \\ Bastian Zimmermann ${ }^{3}$, Frank Kleinjung ${ }^{4}$, Johannes Schuchhardt ${ }^{4}$, Holger Eickhoff ${ }^{5}$ \\ and Friedrich W. Herberg ${ }^{2}$ \\ ${ }^{1}$ Max-Planck Institute for Molecular Genetics, Department of Vertebrate Genomics, Berlin, Germany \\ 2 Universität Kassel, FB Biochemie, Kassel, Germany \\ ${ }^{3}$ Biaffin GmbH \& CoKG, Kassel, Germany \\ ${ }^{4}$ MicroDiscovery GmbH., Berlin, Germany \\ ${ }^{5}$ Scienion AG, Berlin, Germany
}

\begin{abstract}
A variety of different in vivo and in vitro technologies provide comprehensive insights in proteinprotein interaction networks. Here we demonstrate a novel approach to analyze, verify and quantify putative interactions between two members of the S100 protein family and 80 recombinant proteins derived from a proteome-wide protein expression library. Surface plasmon resonance (SPR) using Biacore technology and functional protein microarrays were used as two independent methods to study protein-protein interactions. With this combined approach we were able to detect nine calcium-dependent interactions between Arg-Gly-Ser-(RGS)-His 6 tagged proteins derived from the library and GST-tagged S100B and S100A6, respectively. For the protein microarray affinity-purified proteins from the expression library were spotted onto modified glass slides and probed with the S100 proteins. SPR experiments were performed in the same setup and in a vice-versa approach reversing analytes and ligands to determine distinct association and dissociation patterns of each positive interaction. Besides already known interaction partners, several novel binders were found independently with both detection methods, albeit analogous immobilization strategies had to be applied in both assays.
\end{abstract}

Keywords:

Binding studies / Protein microarray / Protein-protein interaction / S100 proteins / Surface plasmon resonance studies

\section{Introduction}

Currently, the most commonly applied method to identify protein-protein interactions in vivo is the yeast two-hybrid system. Comprehensive, large-scale interaction screens have

Correspondence: Dr. Harald Seitz, Max-Planck Institute for Molecular Genetics, Ihnestrasse 73, 14195 Berlin, Germany

E-mail: seitz@molgen.mpg.de

Fax: +49-30-8413-1139

Abbreviations: RGS-His ${ }_{6}$, Arg-Gly-Ser-His-His-His-His-His-His-; SPR, surface plasmon resonance been carried out [1, 2]. Alternatively, several protein complexes have been identified by tandem affinity purification (tap-tagging approach) followed by protein identification using MS [3, 4].

Despite significant progress in the identification of new interactions partners, consistency between two different methods, e.g., yeast two-hybrid and tap-tagging, and also within the same method is often quite poor [5]. Because of the biological readout, results from yeast two-hybrid studies vary among different labs and different two-hybrid systems. Multiple repetitions of each assay are obligatory to acquire data valid for drawing conclusions on the function of a protein [6]. In contrast, repetitions of interaction experiments 
in vitro under comparable conditions with solid-phase or solution-based protein-protein interaction assays are straightforward.

Recent technological developments like protein microarrays or biosensor analyses using surface plasmon resonance (SPR) allow protein-protein interactions to be characterized with high accuracy and with reasonable throughput $[7,8]$. With the Biacore technology binding partners can be detected in real time and separate kinetic parameters for the association and dissociation phases can be derived. In addition, assay conditions, e.g., buffer components, can be varied quite easily.

Recently, Snyder and co-workers [9] have shown that a proteome-wide microarray analysis can be used to screen protein-protein interactions. The sensitivity and specificity of the approach was demonstrated in a study where only one bait protein out of 10800 showed interaction with a specific prey protein [10].

S100A6 (Calcyclin, 90 amino acids) and S100B (91 amino acids) are cognate members of the S100 family, which are characterized by two EF-hand binding domains for calcium and other divalent ions. Binding of calcium to the EF domains induces a major conformational change exposing hydrophobic domains. This facilitates the interaction with a hydrophobic region of an effector protein, thus eliciting a physiological response. However, this mechanism does not seem to apply to all members of the S100 family $[11,12]$.

In this study, two different methods, protein microarrays and SPR-based biosensor analysis, were used side by side to characterize protein-protein interactions in a solid-phase format. Proteins from a proteome-wide human expression library were expressed with an N-terminal RGS-(His) ${ }_{6}$-tag, purified via Ni-NTA under native conditions and used for subsequent binding analyses. GST-fusion proteins S100A6 and S100B were used to screen a subset of the expression library for interactions. Besides well-known interaction partners [13], several novel binders were identified using either one or both methods.

\section{Material and methods}

\subsection{Purification of His-proteins in a 96-well format}

$\mathrm{N}$-terminally RGS-(His) $)_{6}$-tagged proteins were overexpressed in E. coli SCS1 cells and purified with Ni-NTA agarose in a 96-well format as described by Büssow et al. [14] except for substituting $50 \mathrm{mM}$ Tris pH 8.0 by $50 \mathrm{mM}$ HEPES pH 8.0. Eluates from four independent purifications were pooled for Biacore experiments to compensate for differences in expression level and purification yield. The protein concentration ranged between $10 \mu \mathrm{g} / \mathrm{mL}$ and $500 \mu \mathrm{g} / \mathrm{mL}$ and the molecular mass of each protein was determined using SDS-PAGE, ranging from 15 to $75 \mathrm{kDa}$.
Characteristics of the clones from the human expression library are summarized in Supplementary Material Table 1. Additional information are available via the web interface http://www.proteinstrukturfabrik.de/hex1/CloneSearch.

\subsection{Purification of GST-tagged proteins}

GST (P08515), GST-S100B (P04271) and GST-S100A6 (P06703) were expressed and purified according to the instructions of the manufacturer, concentrated with an Amicon Ultra 10 device to $2 \mathrm{mg} / \mathrm{mL}$ in $2 \times$ PBS buffer and stored at $-80^{\circ} \mathrm{C}$.

\subsection{Protein microarrays}

\subsubsection{Generation of the protein microarrays}

Samples of each RGS-(His) ${ }_{6}$-tagged purified protein $(7 \mu \mathrm{L})$ were transferred to pre-defined positions in a microtiter plate. A dilution series of GST protein served as positive and spotting buffer as negative control. The protein samples were transferred onto FAST $^{\mathrm{TM}}$-slides with Genetix solid pins (X2777, Tip diameter $150 \mu \mathrm{m}$ ) at a relative humidity of $55 \%$. A $2 \times 2$ y-optimized printhead was used, and the in-house modified Genetix QArray was operated by a recently developed control software (Hultschig et al. 2006, in preparation). Pins were inked in $7 \mu \mathrm{L}$ of protein solution for $2 \mathrm{~s}$ and stamped at one position once for $100 \mathrm{~ms}$ using a soft touch spotting distance of $1 \mathrm{~mm}$. After every tenth transfer of one sample or before addressing a new inking position, the solid pins were washed twice for $1 \mathrm{~s}$ with deionized water and once for $3 \mathrm{~s}$ with $80 \%$ technical ethanol and finally dried for $3 \mathrm{~s}$ with oil-free pressurized air (1 bar). In total eight replicates of each protein were evenly distributed over the membrane at non-adjacent positions in two identical fields (defined as the area on an array simultaneously addressed by all pins of printing gadget) each consisting of four different blocks (defined as the area on an array that is described by an individual printing pin of a printing gadget) with $9 \times 13$ spots each and a dot pitch of $346 \mu \mathrm{m}$ (Fig. 1). To locate the protein samples, each block displays an asymmetric pattern due to five additional GST guide dots and a GST dilution series (500-15 ng/ $\mu \mathrm{L}$ GST).

\subsubsection{Screening of FAST $^{\mathrm{TM}}$ slides with anti-RGS-(His) ${ }_{5}$ antibody}

The slides were blocked for $1 \mathrm{~h}$ at room temperature using 2\% BSA/TBST (TBS/0.1\% Tween 20, pH 7.4). Slides were centrifuged briefly and stored at $4^{\circ} \mathrm{C}$ for up to 2 weeks. Before each experiment, the slides were incubated for 23 min at $4^{\circ} \mathrm{C}$ with $100 \mu \mathrm{L}$ reconstitution buffer (TBST with $1 \% \mathrm{BSA})$. The arrays were incubated for $30 \mathrm{~min}$ at room temperature with mouse-anti-penta-His antibody-Alexa Fluor 532 conjugate I (1:1000 in reconstitution buffer) under 
A
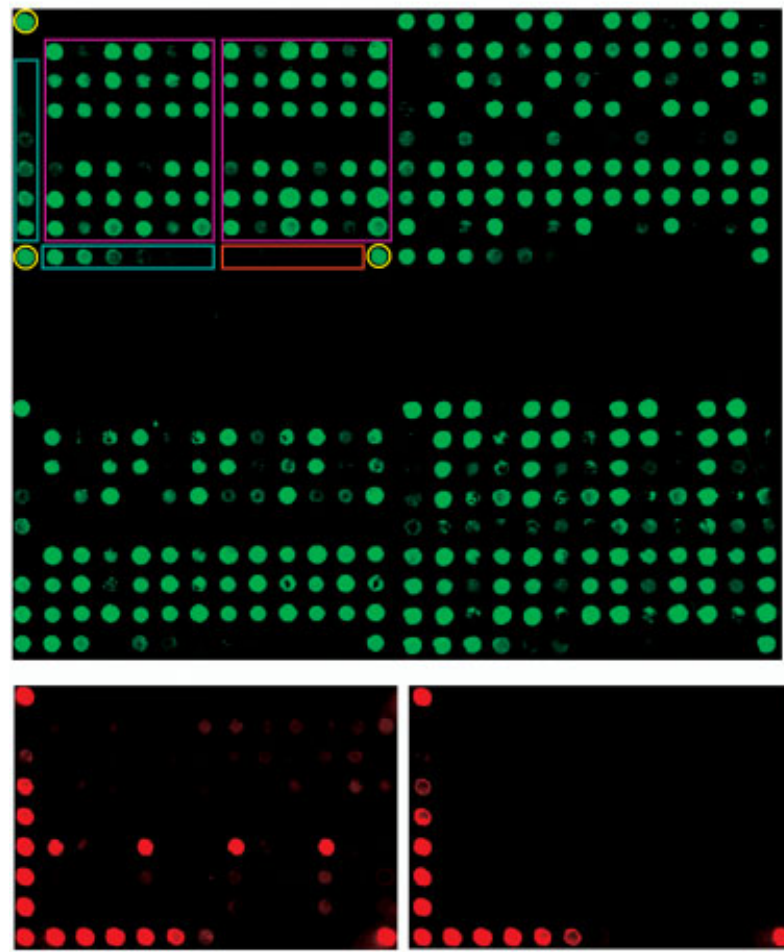

B

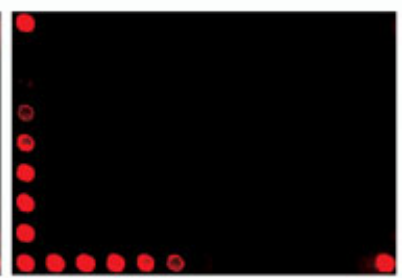

C

Figure 1. Specificity of the interactions between His-proteins and GST-S100 proteins on the protein microarray. His-proteins were arrayed in two identical fields, each consisting of four blocks. Proteins were immobilized in quadruplet from each expression and independent purification and visualized with Cy3-labeled anti-RGS-(His) 5 antibodies. (A) Yellow circles correspond to guide dots in each block. Blue rectangles mark the GST dilution series and orange rectangles the blanks. Light and dark pink rectangles indicate the same proteins from two purifications immobilized in duplicate in the same block. The specific interaction between S100A6 and immobilized prey protein (F2, Q8N1CO) in the presence of calcium (B) and in the absence of calcium (C) is demonstrated. All slides are shown with identical dynamic range after scanning.

light exclusion beneath a cover slide, followed by 15 washing steps $(30 \mathrm{~s})$ with freshly prepared washing buffer (TBS + $0.25 \%$ Tween $20, \mathrm{pH}$ 7.4).

\subsubsection{Screening of FAST ${ }^{\text {TW }}$ slides with GST-tagged proteins}

To analyze the interaction between proteins immobilized on a microarray (prey proteins) and the protein in the mobile phase (bait protein), the slides were first incubated with $100 \mu \mathrm{L}$ reconstitution buffer for $2-3 \mathrm{~min}$ at $4^{\circ} \mathrm{C}$ and subsequently with GST-S100B or GST-S100A6 $(1 \mu \mathrm{g} / \mathrm{mL}$, $30 \mathrm{~min})$, respectively, in the corresponding incubation buffer (20 mM Tris- $\mathrm{HCl}, 0.24 \mathrm{M} \mathrm{NaCl}, 0.005 \%$ Tween 20,

pH 7.5 containing $1 \mathrm{mM}$ EDTA or $1 \mathrm{mM}$ EDTA $+2 \mathrm{mM}$ $\left.\mathrm{Ca}^{2+}\right)$. After washing ten times for $30 \mathrm{~s}$ with washing buffer, the slides were dried by centrifugation for $3 \mathrm{~min}$ at $900 \mathrm{rpm}$ and the spotted surface was immediately covered with $80 \mu \mathrm{L}$ reconstitution buffer. After removal of excessive buffer, the protein microarray was incubated with $80 \mu \mathrm{L}$ anti-GST antibody-Cy5 conjugate (1:400 in reconstitution buffer) for $30 \mathrm{~min}$ at $4^{\circ} \mathrm{C}$. Slides were washed ten times for $30 \mathrm{~s}$ with washing buffer before recording the fluorescence.

\subsubsection{Fluorimetric evaluation of the interactions}

Fluorescence signals were detected on an Affymetrix 428 array scanner at $532 \mathrm{~nm}$ (Alexa 532) and $635 \mathrm{~nm}$ (Cy5 signals), and analyzed with GeneSpotter ${ }^{\mathrm{T}}$ software (MicroDiscovery, Berlin, Germany). For comparable analysis the dynamic range for Alexa 532 and $\mathrm{Cy} 5$ signals was adjusted to the maximum signal intensity below saturation. To compare different slides, fluorescence intensities were intrapolated according to the GST dilution series (reference spots). To compare S100A6 and S100B, the data were normalized by a lowess-transformation implemented into the BioMiner $\mathrm{GS}^{\text {TM }}$ software.

\subsection{SPR studies}

\subsubsection{General}

Analyses were performed at a Biacore 2000 instrument and the data were evaluated with BIAevaluation 4.01 (Biacore AB, Sweden) and Graphpad (Graphpad Prism 4.0, San Diego). NHS, EDC and CM 5 sensor chips were obtained from Biacore AB, Sweden. All other reagents were purchased in the purest grade available. Buffers were degassed and sterile filtrated. Proteins were centrifuged at $4^{\circ} \mathrm{C}$ for $10 \mathrm{~min}$ at $10000 \times \mathrm{g}$ prior to injection.

\subsubsection{Conventional setup}

In the conventional setup the interaction between the immobilized component, the ligand (His-protein, prey protein), and a molecule in the mobile phase, the analyte, (GST fusion protein, bait protein) is analyzed. Changes in the surface concentration are proportional to changes in the refractive index at the surface, resulting in different SPR signals plotted as resonance units (RU); $1000 \mathrm{RU}$ correspond to a surface concentration of $1 \mathrm{ng} / \mathrm{mm}^{2}$ [15].

RGS-(His) ${ }_{4}$ antibody (Qiagen AG, Germany) was used to capture RGS-(His) $)_{6}$-tagged proteins on a CM5 sensor chip for subsequent binding analysis. The RGS-(His $)_{4}$ antibody was dialyzed for $1 \mathrm{~h}$ at $4^{\circ} \mathrm{C}$ against $10 \mathrm{mM}$ sodium acetate buffer, pH 5.0 and immobilized on three flow cells using EDC/NHS chemistry [7]. The antibody $(30 \mu \mathrm{g} / \mathrm{mL})$ was injected for $7 \mathrm{~min}$ at a flow rate of $5 \mu \mathrm{L} / \mathrm{min}$ over the NHS/ EDC-activated surface to generate surface densities of 6500 $8500 \mathrm{RU}$. Subsequently ethanolamine (1 M, pH 8.5) was 
applied to quench unreacted esters. Interaction analysis was performed at $25^{\circ} \mathrm{C}$ in $20 \mathrm{mM}$ MOPS, $150 \mathrm{mM} \mathrm{NaCl}$, pH 7.0 containing $0.005 \%$ surfactant P20.

Recombinant His-tagged proteins from the protein expression library were diluted 20-fold into TNT running buffer $(20 \mathrm{mM}$ Tris- $\mathrm{HCl}, 0.24 \mathrm{M} \mathrm{NaCl}, 0.005 \%$ Tween 20, $\mathrm{pH} 7.5)$ containing $1 \mathrm{mM}$ EDTA or $100 \mu \mathrm{M} \mathrm{Ca}^{2+}$ before injecting them for $5 \mathrm{~min}$ at a flow rate of $10 \mu \mathrm{L} / \mathrm{min}$ sequentially over the three antibody-decorated flow cells. Surface densities between 200 and 3000 RU were achieved.

GST fusion proteins $(25 \mu \mathrm{g} / \mathrm{mL})$ were injected at a flow rate of $30 \mu \mathrm{L} / \mathrm{min}$, and association and dissociation phases were recorded for $5 \mathrm{~min}$ each. Nonspecific binding was subtracted using an activated and deactivated flow cell [7]. Double referencing, i.e., subtracting a blank run with running buffer after subtracting a reference cell, was applied to all curves. Every cycle was finished with two injections of $10 \mathrm{mM}$ glycine pH $1.9(20 \mathrm{~s})$ to remove non-covalently bound proteins from the antibody surface.

\subsubsection{Vice-versa setup}

In a vice-versa setup the interaction between the immobilized ligand (GST fusion protein) and the soluble analyte (Hisprotein) was investigated.

Anti-GST antibody (Biacore AB, Sweden) was coupled as described above. The antibody $(30 \mu \mathrm{g} / \mathrm{mL})$ in $10 \mathrm{mM}$ sodium acetate $\mathrm{pH} 5.0$ was injected for $30 \mathrm{~min}$ at a flow rate of $5 \mu \mathrm{L} /$ min to generate surface densities of about 16 000-19000 RU.

Recombinant GST-S100A6 and GST-S100B were dissolved in TNT running buffer adjusted with different $\mathrm{Ca}^{2+}$ or EDTA concentrations. GST-S100 proteins $(25-50 \mu \mathrm{g} / \mathrm{mL})$ were injected for $1 \mathrm{~min}$ at a flow rate of $10 \mu \mathrm{L} / \mathrm{min}$ to generate surface densities of 500-900 RU.

Recombinant RGS-(His) ${ }_{6}$-tagged proteins were analyzed as described above with blank runs on an anti-GST surface. Double referencing was applied to all curves. After each cycle the surface was regenerated with $10 \mathrm{mM}$ glycine $\mathrm{pH} 2.2$ (six injections of $1 \mathrm{~min}$ each).

\section{Results}

The interaction of S100B and S100A6 was studied with 80 human, recombinant proteins derived from a proteomewide expression library (prey proteins) employing two independent methods. Proteins were purified using native conditions and natively embedded on the protein microarrays (Fig. 1a) to screen for functional binding domains. This should ensure the detection of sequential and/or conformational epitopes. The affinity of His-tagged proteins from two independent protein purifications towards GST-S100A6 and GST-S100B was determined with a fluorescent antibody sandwich on the protein array in the presence of calcium ions. Control experiments were performed in the presence of EDTA without $\mathrm{Ca}^{2+}$ (see Fig. 1b, c).
The protein microarray experiment was performed twice with and without calcium screening for 80 proteins with 8 replicates yielding a total of 1280 interactions for each GSTS100 protein. Thus, the number of replicates allows profound statistical analysis. Proteins from independent preparations were spotted, and in a first analysis step the $\mathrm{S} / \mathrm{N}$ ratio of corresponding protein dots from a single His-protein purification within each slide was determined. A coefficient of variance of $\sim 0.13$ ( $\mathrm{SD} /$ signal mean of 4 spots/set) demonstrates the high quality of the analysis. Interestingly, the results from two different protein purifications showed significant deviations as depicted in Fig. 2, when plotting the signal intensity of a given protein spot of one preparation against the corresponding spot of a second preparation on the same slide (red spots versus blue spots in Fig. 2). However, experiments were highly reproducible when performed on the same prey protein purification, but on different slides or different days, and when analyzed with different batches of bait proteins.

We compared relative signal intensities for the interaction of S100A6 versus S100B to identify specific interactions with prey proteins. Therefore, the ratio of signal intensities (S100A6/S100B) obtained on slide 1 versus the corresponding ratio on slide 2 was plotted for both prey protein purifications (Fig. 3). Spots located in the lower left corner correspond to prey proteins interacting specifically with GST$\mathrm{S} 100 \mathrm{~B}$ and spots located in the upper right corner correspond to prey proteins interacting solely with GST-S100A6. The center of the plot comprises non-unique interactions

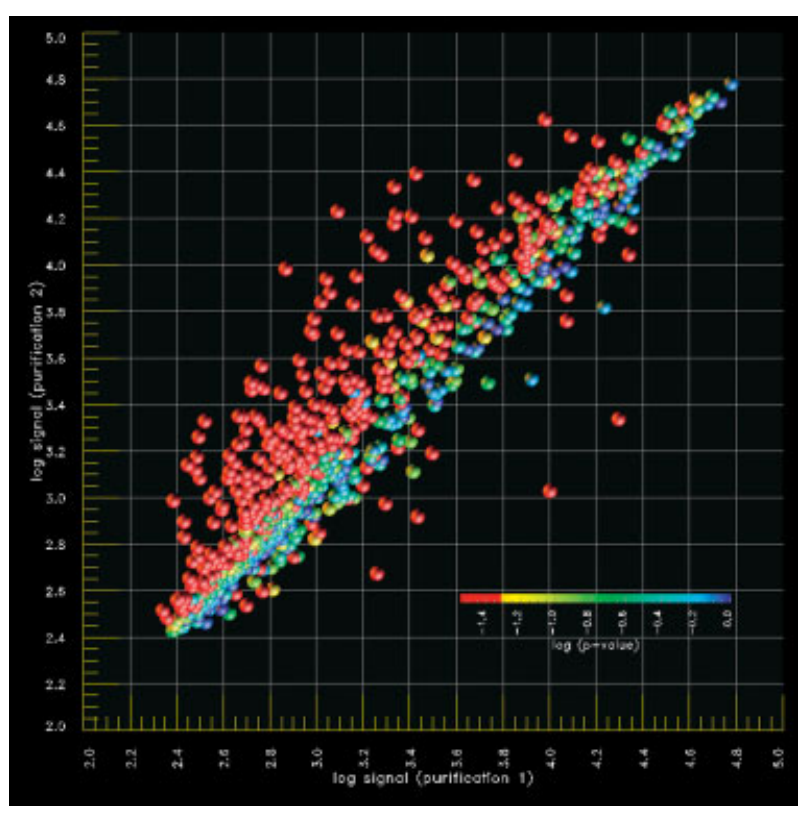

Figure 2. Intra-slide correlation of one representative protein microarray illustrating the difference between two purifications. Colors correspond to the $p$ value $\left(\log _{10}\right.$ scale) of an unpaired Wilcoxon-test performed on two sample sets. Red dots indicate a signal which is significantly different $(p<0.05)$ for both purifications. 


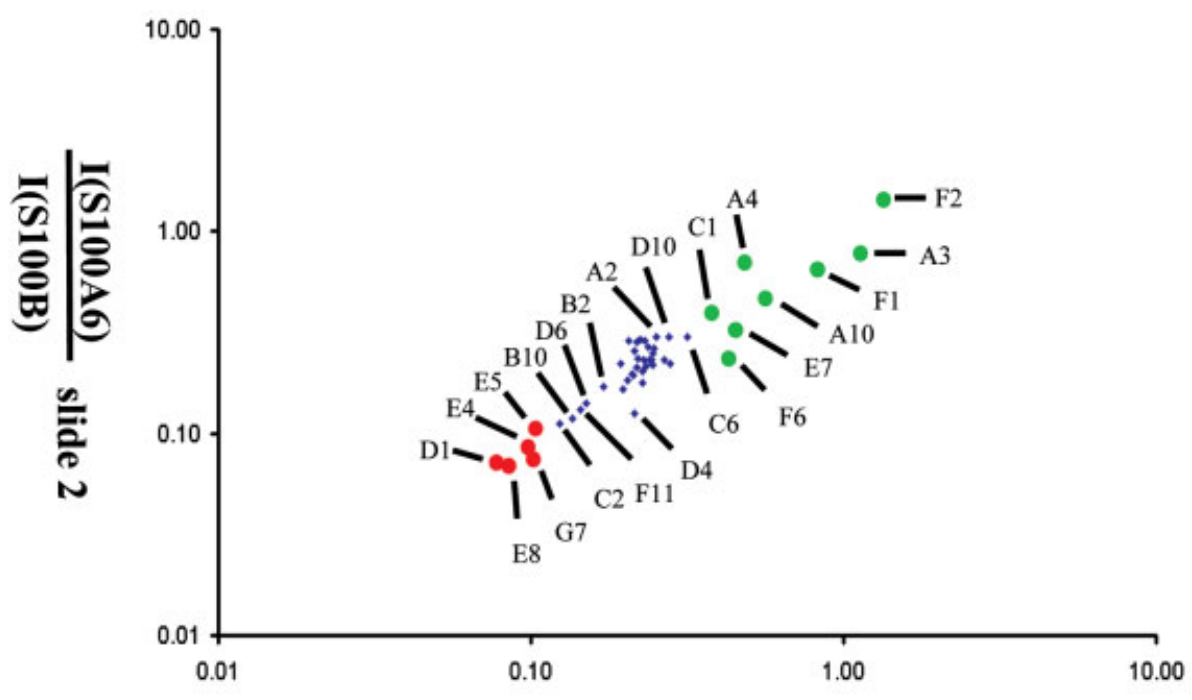

\section{$\frac{\text { I(S100A6) }}{\text { I(S100B) }}$ slide 1}

Figure 3. Calcium-specific interactions of His-proteins with GST-S100 proteins on the protein microarray. To identify calcium-specific interactions of S100A6 or S100B with immobilized prey proteins, relative signal intensities were compared. The ratio S100A6/S100B of slide 1 versus slide 2 was plotted. Red spots indicate proteins interacting specifically with S100B and green spots mark proteins interacting specifically with S100A6. Protein accession numbers are given in the Supplementary Table. with S100B and S100A6. A comparable plot was obtained from the ratio S100A6/S100B for purification 2 (data not shown). The results were not hampered by differences in the absolute fluorescence readout reflected in a correlation coefficient $>0.88$ (not shown), thus demonstrating that differences between both protein purifications (red spots in Fig. 2) have limited influence on the results.

The same set of proteins was analyzed using Biacore technology. Here the GST-fusion proteins S100A6 and S100B were either tested in the mobile phase or when immobilized. His-proteins were either site-directed immobilized to medium density on anti-RGS-(His) ${ }_{4}$ antibody surfaces and the GST proteins were applied in the mobile phase, or the GST proteins were site-directed immobilized to high-density anti-GST antibody surfaces and checked for interactions with His-tagged proteins. As with the microarray experiments, interactions were tested with and without calcium. Bait and prey proteins displaying different binding kinetics were identified. Interactions were categorized into strong, weak and transient binders (Table 1).

Figure 4 shows the association and the dissociation kinetics of S100A6 with the three strongest binders, one weak and one transient binder of the prey library (for details see legend to Fig. 4). Probing S100A6, 9 and 11 from 80 interactions in total were identified using protein microarray and Biacore technology, respectively. From 9 positive interactions for S100A6 derived by the microarray, 6 were also detected with the biosensor, when the His-tagged protein was immobilized to the solid support. Only limited overlap was observed when performing vice-versa experiments using immobilized S100 proteins, presumably due to

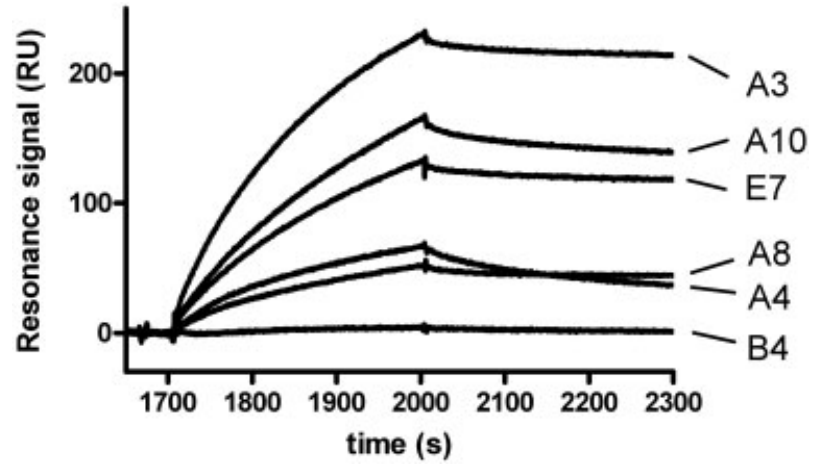

Figure 4. Biacore analysis of GST-S100A6 with His-proteins on anti-RGS-(His) ${ }_{4}$ surfaces. After immobilizing His-proteins to antiRGS-(His) ${ }_{4}$, association as well as dissociation of GST-S100A6 were recorded for $5 \mathrm{~min}$ each in the presence of calcium. Strong interacting partners (A3, A10, E7), a weak binder (A8) and a transient binder (A4) are shown exemplarily. B4 (empty vector) was used as a negative control. Double referencing was performed for all measurements (see Materials and methods).

the immobilization procedure (Table 1). Representative interaction kinetics of prey proteins with immobilized GSTS100B are shown in Fig. 5a.

Using the Biacore approach, transient interactions can be detected. This is, in particular, interesting when analyzing the binding of protein E8 to immobilized GST-S100A6 and GST-S100B (Fig. 5b). E8 interacts strongly with GST-S100B displaying a slow dissociation rate $\left(\mathrm{k}_{\text {diss }}=2.2 \times 10^{-3} / \mathrm{s}\right)$, while the interaction of E8 with GST-S100A6 was only transient $\left(\mathrm{k}_{\text {diss }}=3.2 \times 10^{-2} / \mathrm{s}\right)$. The complex between GST-S100A6 and 
Table 1. Classification of the interaction partners of S100 proteins in strong, weak and transient binders ${ }^{a)}$

\begin{tabular}{|c|c|c|c|}
\hline & Biaco & ology & Protein \\
\hline $\mathrm{S} 100 \mathrm{~A} 6$ & GST & $\mathrm{His}^{1}$ & $\mathrm{His}^{2}$ \\
\hline & $A 8^{d)}$ & $A 3^{b)}$ & $A 3^{b)}$ \\
\hline & $E 8^{b)}$ & $\mathrm{A} 10^{\mathrm{b})}$ & $A 10^{d)}$ \\
\hline & $F 1^{d)}$ & $E 7^{b)}$ & $E 7^{d)}$ \\
\hline & $D 6^{\text {d) }}$ & $A 4^{c)}$ & $A 4^{\mathrm{d})}$ \\
\hline & $\mathrm{F} 11^{\mathrm{d})}$ & $\mathrm{C} 1^{\mathrm{c})}$ & $C 1^{d)}$ \\
\hline & & $F 2^{d)}$ & $F 2^{\mathrm{b})}$ \\
\hline & & $\mathrm{F} 5^{\mathrm{c})}$ & $F 1^{b)}$ \\
\hline & & $A 5^{d)}$ & $\mathrm{C} 11^{\mathrm{d})}$ \\
\hline & & $A 8^{d)}$ & $F 6^{d)}$ \\
\hline & & $A 11^{d)}$ & \\
\hline & & $C 6^{d)}$ & \\
\hline S100B & GST & $\mathrm{His}^{11}$ & $\mathrm{His}^{2)}$ \\
\hline & $E 5^{b)}$ & $E 5^{b)}$ & $E 5^{b)}$ \\
\hline & $E 12^{d)}$ & $\mathrm{E} 12^{\mathrm{c})}$ & $E 8^{b)}$ \\
\hline & $E 8^{b)}$ & $\mathrm{C}^{(\mathrm{c})}$ & $\mathrm{D} 1^{\mathrm{b})}$ \\
\hline & $A 2^{d)}$ & $\mathrm{C} 1^{\mathrm{c})}$ & $E 4^{\text {b) }}$ \\
\hline & & & $\mathrm{G}^{\mathrm{b})}$ \\
\hline
\end{tabular}

a) GST: GST-tagged S100 proteins site-directed immobilized; His $^{1}$ : His-tagged proteins site-directed immobilized; His²: Histagged proteins randomly immobilized.

b) Strong interactions.

c) Transient interactions.

d) Weak interactions.

the prey protein E8 is completely dissociated after $5 \mathrm{~min}$. Thus, only the binding of E8 to GST-S100B was demonstrated on protein microarrays.

Proteins purified from expression plasmids with identical inserts were selected to question the data coherence. F11/D6 (P12277) interacting with S100A6 (Biacore) and E4/ G7 (Q96H25) interacting with S100B (protein microarray, Fig. 3) contain inserts for an identical coding region. Both protein pairs yielded comparable interaction data.

\section{Discussion}

\subsection{General}

Two different chip-based interaction screens were performed to investigate the binding of two members of the S100 protein family (S100A6 and S100B) to a protein expression library. Using a protein microarray, His-tagged proteins (prey library), purified semiautomatically via Ni-NTA, were randomly immobilized on modified glass slides, probed with GST-bait proteins and evaluated based on a fluorescent readout. Alternatively, the same sets of proteins were analyzed using SPR on a Biacore instrument. Here either the prey proteins or the bait proteins were site-directed immobi-
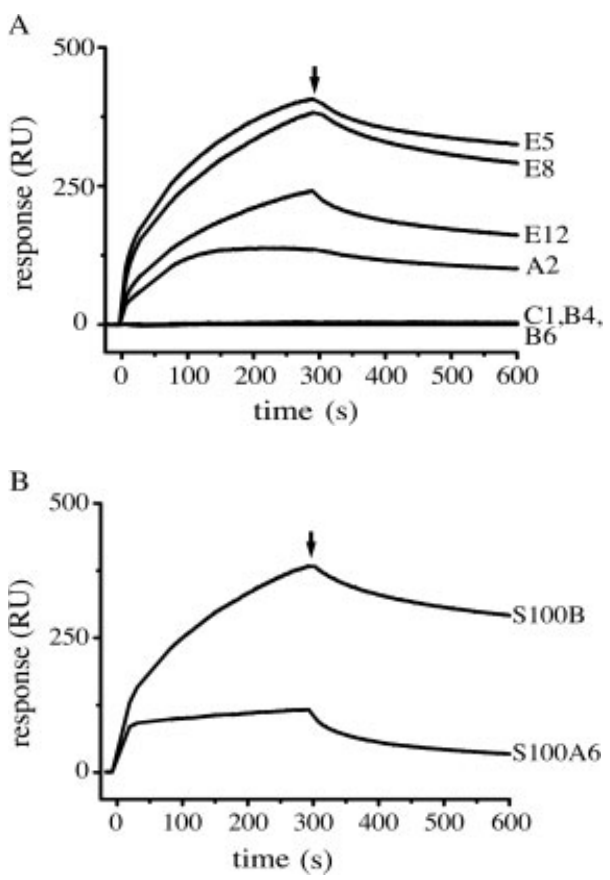

Figure 5. Biacore analysis of His-proteins with GST-S100 protein immobilised on anti-GST surfaces. (A) RGS-(His) ${ }_{6}$-tagged protein interaction with GST-S100B on anti-GST surfaces. The arrow indicates the end of the injection of the His-proteins. (B) Calciumdependent interaction of the RGS-(His) ${ }_{6}$-protein E8 on anti-GSTS100A6 surface (lower trace) and anti-GST-S100B surface (upper trace).

lized employing a specific capture approach [7], and analyzed with respect to their detailed binding kinetics using the complementary interaction partner in a microflow system.

We limited the number of interactions ( 80 prey proteins and 2 bait proteins with or without $\mathrm{Ca}^{2+}$ ) to analyze all interactions with both methods. Only interactions detectable in the presence of $\mathrm{Ca}^{2+}$ were used for further analysis. No specific interactions in the absence of $\mathrm{Ca}^{2+}$ were detected.

In the protein microarray, prey proteins were spotted in eight replicates. A stringent statistical analysis could thus be applied to datasets selecting for high-quality data (high $\mathrm{S} / \mathrm{N}$ ratio). In the protein microarray experiments only 41 proteins passed this threshold. From these, 9 proteins were shown to interact with S100A6 and 5 proteins with S100B.

Using Biacore, both bait proteins and all but 7 from the 80 prey proteins could be immobilized on a sensor chip to a level allowing an interaction analysis (more than 50 response units). Here, 15 and 6 interactions were detected with S100A6 and S100B, respectively. Seven prey proteins for S100A6 and 2 prey proteins for S100B overlapped between both techniques (Table 1). Fewer interactions could be recorded for S100B with both methods (Table 1). Interestingly, when comparing the numbers of positive interactions in dependence on the immobilization strategy using the same technology (here Biacore), less overlap was observed (1 for S100A6 and 2 for S100B, Table 1). 


\subsection{Immobilization strategies}

These results reflect the importance of the immobilization strategy on the outcome of solid-phase interaction screens. Not too surprising, the way of immobilizing proteins (random versus site-directed and choice of the fusion part) has a stronger influence on both the interaction generally and the kinetics of a given interaction than the method of detection. Random immobilization on nitrocellulose membranes or on dextrane-coated sensor chips may cause steric constraints or may generate crowding effects independent of the method of detection [16]. A lot of development has been performed to generate sensor surfaces providing an environment suitable for biological interaction with low unspecific binding and high binding capacity. Long-chain dextrans with a low degree of cross-linking have been demonstrated to be suitable for immobilization in the Biacore technology. Furthermore, retaining the biological activity during the immobilization [17] and the interaction assay is important. It has been shown previously that an interaction can be detected by immobilizing one interaction partner and probing the other in the mobile phase; however, the same interaction pattern could not be observed when performing the vice-versa experiment [18]. Repetitive immobilization and regeneration of antiRGS-(His) ${ }_{4}$ antibodies may reduce the biological activity. Therefore, control experiments had to be performed as shown before [7].

At present, for protein microarrays, nitrocellulose-coated slides are the most reliable surfaces for measuring proteinprotein interactions as the 3-D structure of the layer offers a high protein binding capacity [19].

\subsection{Interaction analysis}

Using Biacore, glyceraldehyde 3-phosphate dehydrogenase (GAPDH, A8, P04406) was identified as an interaction partner for S100A6 in a strictly calcium-dependent manner. The interaction was verified using two immobilization strategies on the SPR-sensor. Previously, the calcium-dependent binding of GAPDH to S100A6 was demonstrated by affinity chromatography [20]. Interestingly, A8 did not pass the stringent criteria of the protein microarray analysis.

Seven proteins were revealed as interaction partners for S100A6 in vitro based on both methods: a proteasome inhibitor subunit (A3, Q92530), ubiquitin B (A4, Q9BWD6), p53 and DNA damage-regulated protein (A10, AAP45329), a glutathione-transferase (C1, P08263), a ribosomal protein (E7, AAH17321), alpha-2-macroglobulin receptor-associated protein precursor (F1, P30533) and a cadherin-associated protein (F2, Q8N1CO).

Under stringent conditions, two proteins from the expression library, a ubiquitin ribosomal fusion product (E5, Q9BX89) and a putative RNA binding protein (E8, Q9BV96), were identified as interacting with S100B using both methods. Vimentin (C7) interaction with S100B had been postulated before utilizing immunohistochemistry. S100B binding to the N-terminal domain of glial fibrillary acidic protein (GFAP) embedded like vimentin in intermediate filaments (Ifs) was demonstrated [21-23]. Vimentin matches the consensus sequence for target proteins of S100B [24]; however, the interaction had not been verified in in vitro experiments so far. In this study, no direct interaction was shown using either method.

Accordingly, protein-protein interaction studies utilizing immobilized proteins can generate meaningful results once careful assay design has been taken into consideration. Our data clearly demonstrate that the characterization of the investigated interactions is strongly dependent on the immobilization strategy and on the presence of cofactors. These parameters may influence interaction patterns more than the technical setup applied for the detection, e.g., functional microarrays or SPR in a flow system.

We wish to thank Christine Gotthold and Ulrike Borgmeier for technical help and Thomas Nitsche and Thomas Przewieslik for engineering support. This work was funded by the German Ministry for Research (BMBF grant 01GR 0472 and 01GR 0441), the EU project (MolTool, LSHG-CT-2004-503155 and proteome binders, 026008 (RICA)) and the Max-PlanckSociety.

\section{References}

[1] Hua, S. B., Luo, Y., Qiu, M., Chan, E. et al., Gene 1998, 215, 143-152.

[2] Fromont-Racine, M., Rain, J. C., Legrain, P., Nat. Genet. 1997, 16, 277-282.

[3] Ho, Y., Gruhler, A., Heilbut, A., Bader, G. D. et al., Nature 2002, 415, 180-183.

[4] Gavin, A. C., Bosche, M., Krause, R., Grandi, P. et al., Nature 2002, 415, 141-147.

[5] von Mering, C., Krause, R., Snel, B., Cornell, M. et al., Nature 2002, 417, 399-403.

[6] Bader, G. D., Hogue, C. W., Nat. Biotechnol. 2002, 20, 991997.

[7] Hahnefeld, C., Drewianka, S., Herberg, F. W., Methods Mol. Med. 2004, 94, 299-320.

[8] Feilner, T. K.,J., NiemannB., , Kramer, A., Possling, A., et al., Curr. Proteomics 2004, 1, 283-295.

[9] Zhu, H., Bilgin, M., Bangham, R., Hall, D. et al., Science 2001, 293, 2101-2105.

[10] MacBeath, G., Schreiber, S. L., Science 2000, 289, 1760 1763.

[11] Sastry, M., Ketchem, R. R., Crescenzi, O., Weber, C. et al., Structure 1998, 6, 223-231.

[12] Heizmann, C. W., Cox, J. A., Biometals 1998, 11, 383-397.

[13] Donato, R., Biochim. Biophys. Acta 1999, 1450, 191-231.

[14] Buessow, K., Quedenau, C., Sievert, V., Tischer, J. et al., Genome Biol. 2004, 5, R71.

[15] Stenberg, E., Persson, B., Roos, H., Urbaniczky, C., J. Colloid Interface Sci. 1991, 143, 513-526. 
[16] Herberg, F. W., Zimmermann, B., in: Hardie, D. G. (Ed.), Protein Phosphorylation-A Practical Approach, Oxford University Press, Oxford 1999, pp. 335-371.

[17] Gesellchen, F., Zimmermann, B., Herberg, F. W., Methods Mol. Biol. 2005, 305, 17-46.

[18] Herberg, F. W., Maleszka, A., Eide, T., Vossebein, L., Tasken, K., J. Mol. Biol. 2000, 298, 329-339.

[19] Hultschig, C., Kreutzberger, J., Seitz, H., Konthur, Z. et al., Curr. Opin. Chem. Biol. 2006, 10, 4-10.
[20] Filipek, A., Wojda, U., Lesniak, W., Int. J. Biochem. Cell Biol. 1995, 27, 1123-1131.

[21] Sorci, G., Agneletti, A. L., Bianchi, R., Donato, R., Biochim. Biophys. Acta 1998, 1448, 277-289.

[22] Sorci, G., Bianchi, R., Giambanco, I., Rambotti, M. G., Donato, R., Cell Calcium 1999, 25, 93-106.

[23] Ziegler, D. R., Innocente, C. E., Leal, R. B., Rodnight, R., Goncalves, C. A., Neurochem. Res. 1998, 23, 1259-1263.

[24] McClintock, K. A., Shaw, G. S., Protein Sci. 2000, 9, 20432046. 